\title{
Beyond Zero Waste Concept: A Revolution for Sustainable Community
}

\author{
Mianda Khattab* and Salah El Haggar \\ Environmental Engineering Department, The American University in Cairo, Egypt
}

\begin{abstract}
A community reflects a big number of citizens grouped in an area, sharing common characteristics, traditions, lifestyle and daily needs. People within a community will affect the area and surrounding citizens as per their daily acts and traditions as well as being affected by the surrounded environment too; meaning that the community and the people living within are interconnected where the action of one end will lead to a reaction in the other. Thus there is a need to introduce the concept of sustainable communities, which focuses on water, air quality, wastes, energy and materials being more of a marketing word nowadays to companies, industries, governments and communities. However, since natural resources are being abused to a big extend that currently some living categories cannot access. This leads to widening the gap between the rich and the poor thus diversifying the community. In addition to, negative actions are impacting the surrounding environment leading to an undesired living standards and lifestyle like the accumulation of wastes and the consequent rise of diseases and pollution. In brief, the objective of this paper is to propose a zero waste practical approach for urban communities, hoping to reach a common ground of understanding. While also having defined set of actions towards having a balanced environment and ecosystem for a better, balance, pollution-free life and natural resources management for future generations' needs.
\end{abstract}

Keywords: Sustainable Community, Sustainability, Cradle-to-Cradle Concept, Zero-Waste Concept, Waste Management

\section{Introduction}

A community is a public access place where there are common things shared together with the community members, it can sometimes be divided into sub-communities which are often interconnected formulating the traditions and habits of the bigger community. For instance an urban community can be divided into residential, medical, educational and business communities, when they are interconnected they align with the bigger community pre-defined image. It is important to understand the surrounding community as it is the place where a person belongs while sharing information and holding social interactions. This helps in ensuring easy communication between community members for a convenient living that will lead to a dynamic and interactive living aiming at enhancing the community. (Community Health and Development, 2015).

Urban Community is the most important type of communities as it is counted to be the biggest landscape area with a high density of population when compared with rural and other communities.

* Corresponding author

E-mail: miaz@aucegypt.edu

(C) 2016 International Association for Sharing Knowledge and Sustainability

DOI: $10.5383 /$ swes.8.01.004
As shown in Figure 1, in the year 2000 the total population in urban areas worldwide was counted to cover $47 \%$ which is approximately 2.8 billion people and it is projected to increase by 2025 to $60 \%$ (University of Michigan, 2006). In addition of being a more stable community for both individuals and families while offering more job opportunities as it includes industries, businesses and commercials, leading to the need for different specializations for work. In other words, an urban community will then be diverse in habits, customs, traditions and religious beliefs as well as class levels extremes between community members (Mondal, 2015). Thus an urban community is the center of attention in any country and it should reflect more of sustainability acts, more of better lifestyle and economical standards. 


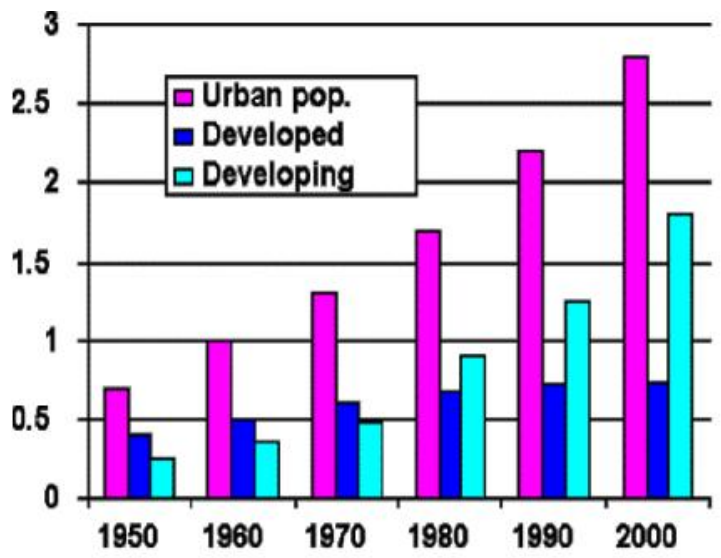

Figure 1: Urban Population Rate (University of Michigan, 2006)

\section{Impacts of Urban Community on the Environment}

With the high level of urbanization and the urge of having a better lifestyle in line with the increase in the number of industries serving more daily needs thus natural resources are being not only used but consumed and abused so as to meet these exceeding needs. The produced products which are consumed by customers are facing a problem in environmental disposal leading to an increase in the environmental pollution in air, water, energy, material, land and soil. As time is passing and natural resources are being used each day more than the other, this will lead to a depletion of the available possessions gradually leading to a scarce society. This will not be able to meet the needs of the current so as to account for the future generations in addition to living a pollution-full environment. In brief, currently urban communities are causing a threat on the surrounding environment that if maintained as is, this will lead to a more unstable ecosystem and community. That is why the introduction of sustainable community concept which reflects acts on land, water, air, energy and materials is important; however, the main focus of this paper will only be on waste management according to zero waste concept as it is considered the highest category of pollution and materials abusing mode in addition to its impact on land, water, air and soil. So there is a need for a sustainable community according to (Smith, 2008) where citizens has to ensure their right of having:

1. Acceptable air and water quality.

2. Acceptable healthy food

3. Proper Life style

4. Acceptable Education Level in a lively culture.

5. Encouraging the inhabitants for a satisfying working level

6. Public Places safety, freedom of the citizens yet serving to their own rights and welfare.

7. Equality of rights and job opportunities should be present, regardless of the age, sex, religion, nationality, color, etc.

8. Proper public transportation being accessible to each living standard citizen, also properly maintained for old people and disabled ones.

Reaching a sustainable community will lead to a better lifestyle that is full of secure and encouraging atmosphere for a more productive living. It will also lead to less urge to travel to somewhere less polluted or less dense.

\section{Waste Characteristics}

Wastes being defined as getting rid or throwing of used and no longer needed materials in trash bins. It is varying directly proportional on the population number in line with the enhancements technology is growing through and materials used to produce the needed product. Lately, as wastes started to accumulate in the streets and landfills as pollution level started to increase for example, visual pollution, air pollution which results from burning of wastes, land and soil pollution. This happens by the accumulation of wastes in landfill left over for natural degradation which can take up to years, the rise of diseases resulting from the attraction of flying insects and animals to the "waste accumulated lands" and lastly, the most noticed and un-solved problem of natural resources depletion. Communities are heading backwards by ignoring the negative effects waste accumulation and improper utilization is leading to. Thus there is a need to study sustainable communities, waste management process that when followed or abided to will lead to the enhancement of lifestyle.

\section{Urban Community and Sustainability}

As an urban community is considered to be the densest type of communities in comparison with rural, tourism and suburban communities. Urban communities are defined as big cities or towns in general that include all types of activities involving a full citizens' lifestyle on a regular basis unlike tourism industry for instance which is a seasonal community primarily present for entertainment and leisure. Urban communities should include but not be limited to residential areas, food, drinking, schools/ universities, work places, industries, factories, entertainment areas, shopping malls and resorts for tourism focus and leisure. Saying that about urban communities and how densely populated they are, leads to introducing facts about waste generated in such high population cities. As technology is always in advancement in terms of products offered, different features and different materials being used for a non-corrosive product, non-scratch able material, and water resistant materials. For instance, this all leads to the introductory of new materials compositions that are studied on how to produce but not how to reuse or recycle thus they tend to be disposed leading to an increase in the level of wastes dumped in landfills for instance. In addition to the difference in society cultural levels and areas, the waste types will differ; when comparing the types of wastes/ waste composition and quantities found in moderate and rich areas, they tend to be different and slightly more that poor areas whose citizens have low access to products affordability and resources, this reflects back on the wastes characteristics, composition and density. Yet at the end of the day all types of wastes from different areas are being collected and disposed in the same manner regardless if they are in a poor or rich side of the urban community. Mentioning the different types of wastes that are generated from an urban community in general and as shown in Figure 2. An urban community includes residential areas, industries, commercials like stores, hotels and office buildings, institutional like schools and hospitals, Construction and Demolition wastes (C\&D) which result from renovation sites, new construction sites or demolition of buildings. Also, municipal services wastes that result from cleaning the streets, landscaping, wastewater treatment and recreational areas and lastly, agriculture wastes like crops and greeneries. The types of waste generated are categorized as paper, plastics, cardboards, metals, food wastes, hazardous wastes, ashes, wood, steel, concrete, industrial process wastes and pesticides (Tadesse, 2004). 


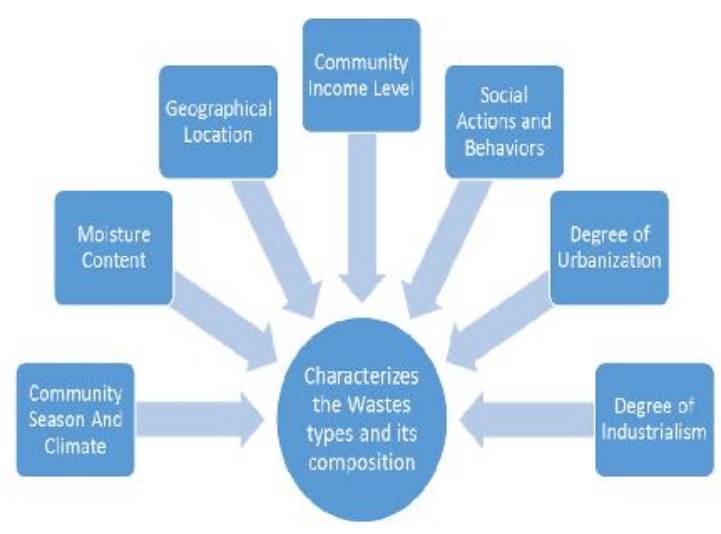

Figure 2: Urban Community Wastes characteristics, composition and density (Gaurav K. Singh, 2013

Before analyzing how to utilize resource and waste management and after understanding the characteristics of waste types and composition as shown in Figure 3; defining the sources of wastes in urban community is essential in understanding the types of wastes produced by each subcommunity category and how sustainably they can be utilized. Industries with different types are consuming a lot of materials and producing massive amounts of wastes and rejects in return. In addition to commercial and business buildings which are famous with the leftover paper and cardboard wastes. Organic wastes are common types of wastes mainly in residential buildings, landscapes wastes and agricultural wastes for agricultural areas and lands, municipal services like street cleaning water and chemicals wastes types being disposed in drainages and lastly construction and demolition (C\&D) wastes which are categorized in asphalt, bricks, wood,...etc.

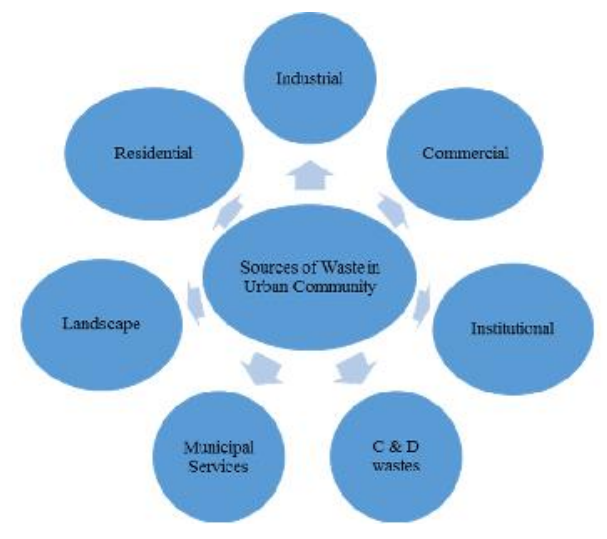

Figure 4: Sources of Waste in Urban Community

A common misconception for many citizens, organizations and governments is that wastes are un-needed leftovers; however, the end of product waste can be used in the regeneration of another product or energy source input to another process. As the community is a closed loop where the inputs at one stage will be the output at another meanwhile after processing they can be the inputs again for another process as illustrated in Cradle-to-Cradle concept (El-Haggar, 2007). Afterwards, introducing a modified technique for wastes management will be proposed in this paper, but before doing that, understanding the most common waste management process will assist in identifying the current mindset of people and how to enhance the thinking strategy for a more sustainable acts. Figure 4 shows the most common waste management process that has been used worldwide in most of the developing and developed countries for decades. Starting with on-site handling meaning waste management or segregation at home or facilities and industries and it usually relies primarily on awareness and the presence of the needed tools and materials.

\section{Traditional Waste Management}

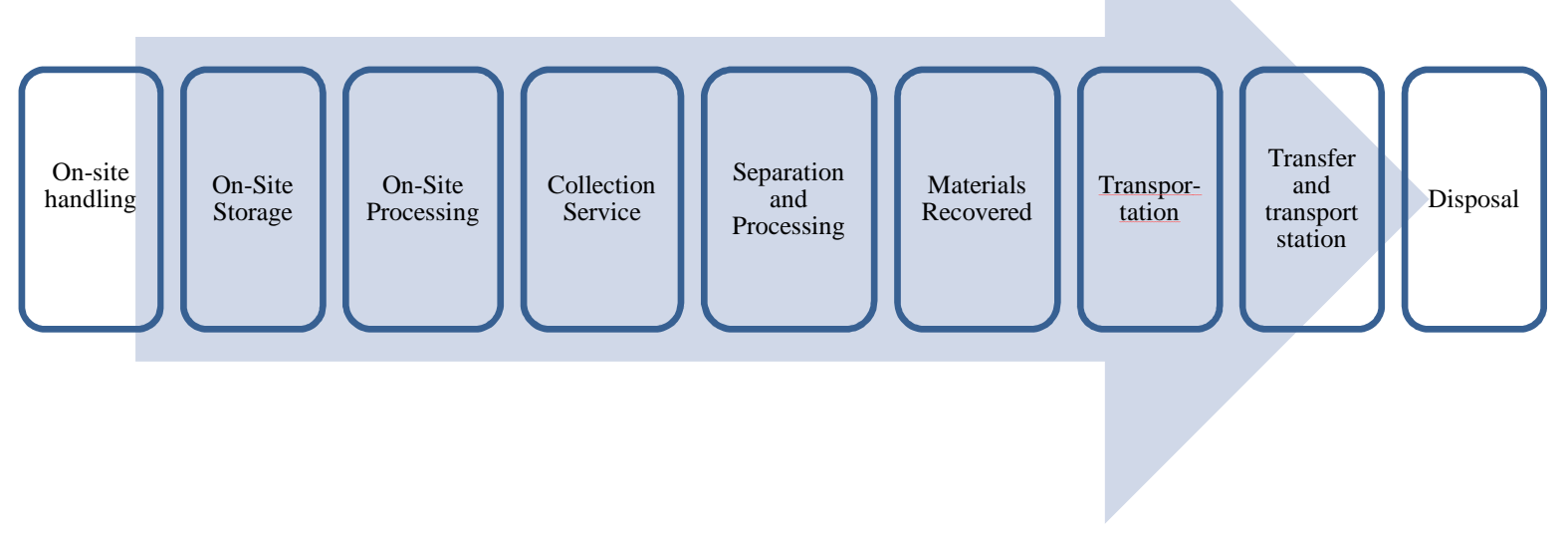

Figure 3: Waste Management Process 
These supportive tools are like storage containers, different trash bin bags colors referring to different types of wastes and in front of the building collector or container. Then the wastes collected will go to an on-site storage and processing that is divided into the collection process on how the wastes are collected and placed from home to the waste management facility and collection system which refers to the types of equipment used like collectiontrucks.

Moving on to the collection system which is the act of the trucks being on a schedule for specific number of daily/ frequency of collection rounds to collect the trash in the collector bins in front of the buildings or facilities. Wastes are being sent to transfer stations where it is separated under recycling or disposal which is the main rise of problems and easy task to do. This includes dumping of wastes in an open dumping site which is usually smaller than a landfill. The problem with open dumping is the creating of odor, attraction of insects and animals, insufficient usage of the land and surrounding ones. Incineration is the second dumping process of burning garbage components, mainly combustible ones. As much as incineration helps in getting rid of un-needed wastes and producing heat for power from burning them. However, the problem with that is the generation of air pollution besides its cost of designing and building. Lastly is the composting of organic waste where there is natural degradation of wastes; as much as it could be counted as one of the best utilization methods yet the $\mathrm{pH}$ level, moisture content and carbon to nitrogen ratio should be maintained and managed so as to achieve the needed biodegradation results (Tadesse, 2004). With reference to all the major problem remains unsolved, now with the problem of increasing number of population and high needs limits accordingly. Thus industries tend to use more of the natural resources to produce the needed amounts of good and services and this leads to abusing the available resources which are scarce. This leads to the introduction of a concept that is not new, however it has been considered more of a philosophy than a needed solution strategy that is doable in reaching a sustainable and environmentally friendly community via proper waste usage, re-usage and recycling; this concept is known as the Zero Waste Concept.

\section{Zero Waste Concept}

Zero waste is a strategical goal or more of a philosophy and a principle of design that was introduced in the early 1970 s having different definitions as per the level of understanding and awareness to different community members. However most of them are centered about the concept of recycling for a whole system or a full product lifecycle so as to minimize the produced wastes and accordingly maximize the recycled products. Zero Waste varies in how its definition is introduced for instance in the Japanese Industries zero waste is known as zero defected products. Other definition is that "zero waste is a practical theory on how to obtain maximum efficiency from the use of resources" as defined by the Zero Waste Institute [ (European Regional Development Fund, 2015) \& (GrassRoots Recycling Network, 2015)].Zero waste started in 1970s by community recycling programs pioneers however it was considered as a design approach rather than a source of solutions for a better living. Later on in the early 2000s Zero Waste was referred to as a practical theory to maximize production efficiency. And by Mid 2001 Zero Waste in New Zealand had a future approach till 2020 defining it as an eliminating tool rather than a waste management method aiming at a change in the way material are introduced in a production process. In addition to defining how the materials are managed in the society and then how are they returned back into products, this is from the environmental standard. Looking at the economic point of view, Zero Waste is defined as a way to transform the present cost into a more value added resources that should be used by the industry.

Last but not least, for the social point of view, Zero Waste will provide a self-sustained community that will provide job opportunities, better livings, and efficient lifestyle.

This will better the current economic stands which will reflect on the surrounding social life within the community. Lastly, it is focused on excluding any concept for landfills, disposal fees and illiteracy of waste management while including environmental designs, educational programs within the schools, trainings and research studies, green regulations, branding for zero waste businesses and including resource recovery infrastructures (European Regional Development Fund, 2015). As per the Institute for Zero Waste in Africa (2015) which identified the below common zero waste beliefs among people giving wrong or misleading information about it, and maybe that is why Zero Waste concept is always seen as a philosophical concept rather than a design strategy.

- Redesigning products and packaging: Implementing a clear and clean design and production technique starting with the planning of natural resources usage till minimization of the recovered materials through the production process is one of zero waste aims.

- Producer Responsibility: The manufacturer is held responsible physically and financially for the "cannot be recycled" types of wastes; and this prevents or decreases the presence of waste in the incinerators or the landfills.

- Infrastructural Investment: Encouraging the community to invest in new resource recovery facilities instead of using the tax money in increasing the landfills or new incinerators.

- Monetary Efficiency: Applying taxes and introducing policies that makes that prevents any usage of natural resources by manufactures and finding an alternative way to produced products is a must.

- Job Creation: If the waste in the incinerators and landfills were usefully re-processed again to be reproduced in other forms of products, this would certainly help the society environmentally and economically by introducing almost 10 times more and new job opportunities.

\section{Zero Waste Concept and Cradle-To-Cradle}

One of the new sustainability generated concepts is "zero waste" which is referring to studying the use of resources for long term efficiency. Zero waste can be achieved efficiently while following the Cradle to Cradle approach (El-Haggar, 2007). The concept behind the sustainable urban communities is to follow cradle-to-cradle approach. As shown in Figure 5 it is a close loop starting with the raw materials extraction from earth (cradle) till it is returned back sustainably to earth following a safe utilization process. This process starts with raw materials extraction going through the needed processing and manufacturing of materials then packaging to be transported to the corresponding factories or stores then used in homes and then the wastes are divided into recyclable or reusable wastes. The wastes are collected and sent to a transfer station which will check for the needed recycling ones to be done on-site, else if any recyclable material cannot be done on-site then it will be sent to an off-site recycling. 
And this is to ensure to optimum and most efficient use of resources and reusing of products.

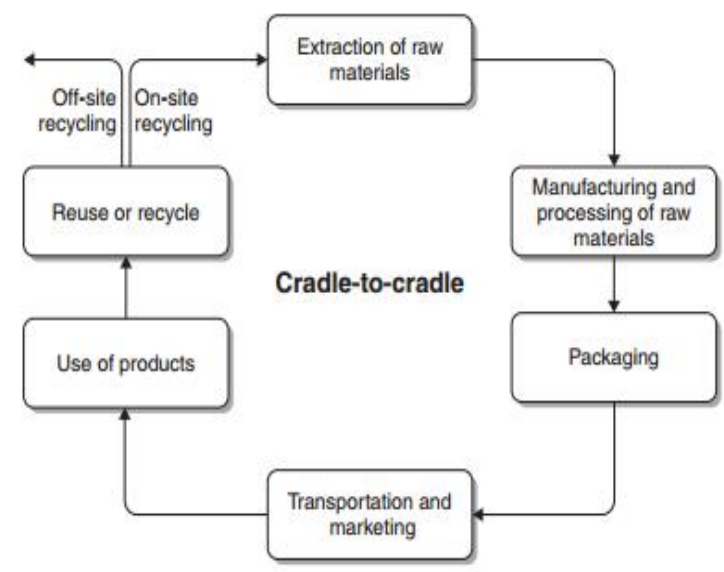

Figure 5: Cradle-to-Cradle Approach (El-Haggar, 2007)

\section{CASE STUDIES}

Below are some case studies showing how Zero Waste Concept has started and evolved in two different countries, Sweden and USA.

\section{A. Sweden's Recycling Revolution (The Swedish Institue, 2013-2015)}

With a population less than 10 million person, starting with recycling $38 \%$ of household wastes, which are the daily usage products leftovers as bottles, organic food, cans, newspaper... etc., in 1975 to being almost the largest and first country to recycle more than $99 \%$ of household wastes. Half of the household wastes that are collected are being burnt to be used as a source of energy, knowing that Sweden does import wastes from other countries so that it can increase its energy level production, while focusing on reusing materials in another form even so as to ensure less energy is being used in creating a new one from scratch.

Wastes are being separated into different categories like newspapers to be turned into paper mass, lightbulbs, batteries, glass, bottles to be reused as new items, metal, and even food wastes are to be separated into those being recycled, reused or composted to ensure that whichever is sufficient has been used as biogas or soil; while purifying the wasted water to a big extend to be potable.

\section{B. Proctor \& Gamble - USA (Business Sector Media, LLC, 2014)}

As $P \& G$ has committed to produce sustainable brands, that by 2020 it will be sending zero wastes produced by manufacturing to landfills by applying zero waste concept which it defines as "zero manufacturing waste disposed directly to landfill or incineration without energy recover by the site, except where local legal requirements specify that regulated wastes must be disposed in a landfill". P\&G is working towards improving packaging and design of the product by a "lifecycle thinking", which is reflecting back on a sustainable brand which started through a consumer sustainability study which conducted that minority of consumers believe in any environmental named product and are willing to buy these products even at higher prices and lower performances. However the majority of consumers are not willing to go for this trade off specially when it comes to paying more for a commodity that will not meet their needs fully; thus $P \& G$ decided to enhance their product strategy to be from "sustainable and nice to have" to need to have", an example to that is their study to producing a washing machine soap that would help users in washing using cold water without any decrease in performance while also converting $70 \%$ of washing machine load. Another lifecycle thinking approach is by reducing production process produced solid waste.

\section{Proposed Zero Waste Concept for Urban Sustainable Community}

The flowchart in Figure 6 introduces a cradle-to-cradle zero waste concept model for a sustainable zero waste Urban Sustainable Community (U.S.C) which produces municipal solid wastes (MSW) which are defined to be the daily wastes; being divided as non-organic MSW and Organic food wastes. All of the wastes are collected from the U.S.C. where the nonorganic MSW are being sent into a transfer station which is defined as waste management sites allowing for safe waste utilization systems unlike landfills (El-Haggar, 2007). The collection trucks transfer/unload the wastes from a location to the transfer station. In a transfer station facility the wastes are further separated and larger trucks can send the segregated wastes into recycling facilities, that the recyclables or products and materials that can be reused are being transferred to their facility of specialty and after being recycled or modified for reusing; the products such as coat hangers and waste plastic bags are resent back to the U.S.C. and this aims at environmentally reusing the generated wastes (by recycling or reusing) also minimizing the amount of natural resources needed to produce new products and this all leads back to another closed loop of MSW from and to U.S.C as shown in Figure 6 . Then the construction and demolition (C\&D) wastes which result from destruction of an existing building in an existing community or the construction of new buildings in new and existing communities. The types of wastes extracted from this phase can be categorized as ceramics, marble, bricks, concrete in addition to many other materials that when processed can result in other construction and materials such as paving interlocks, bricks, plainconcrete,...etc. Municipal Liquor wastes, also known as sewage wastes are another type of wastes being produced in the U.S.C. This type of waste will be treated by sewage treatment processes to produce sludge and effluent or safe reusable water. The effluent can be used in irrigation systems, cleaning modes or for the AC's cooling towers while the sludge will be mixed with other organic waste for a co-composting process (El-Haggar, Sustainable Industrial Design and Waste Management, Cradle-to-Cradle for sustainable development, 2007) as described in Figure 6. 


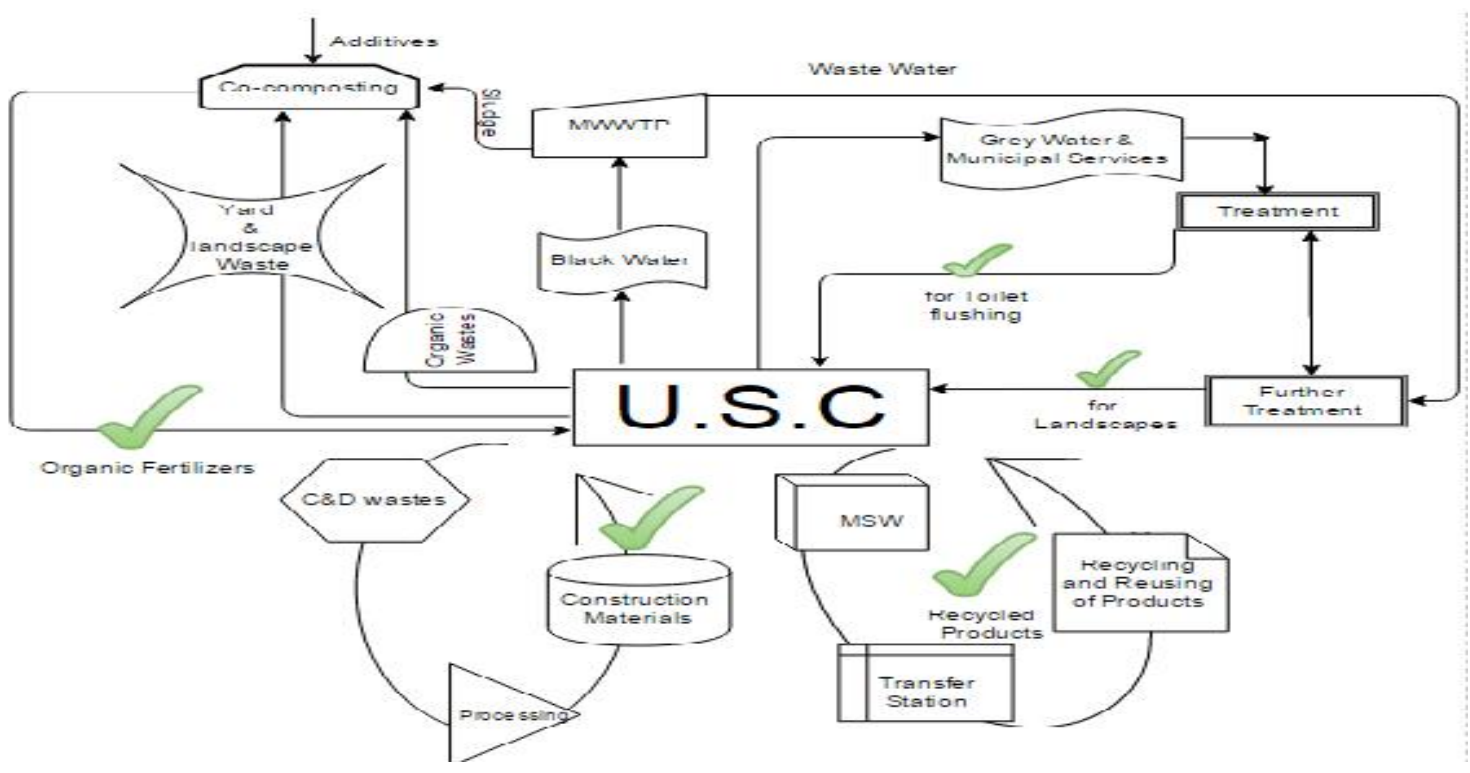

Figure 6: Proposed Zero Waste Concept for Urban Sustainable Community

Then the black water going to a Municipal Waste Water Treatment Plant (MWWTP), the organic food wastes in line with yard wastes, grass and leaves wastes will undergo cocomposting. Co-composting is aerobic waste decomposition process where the waste is stacked in piles for fermentation using the sludge produced from the municipal liquor wastes (sewage wastes) loop discussed above. These in addition to some additives like rock phosphate, potassium, etc. which are to be added to adjust the desired output from the co-composting stage which are organic fertilizers. These organic fertilizers will be used for organic farming and can be added on the golf land or green areas within the U.S.C so as to increase its fertility and this will be the forth closed loop within the U.S.C community. Lastly, for the grey water produced from the U.S.C, it will undergo treatment so as to be re-used again in toilet flushing, and the excess of grey water with the excess of black water discussed earlier can undergo further treatment to be used for landscape and irrigation. The sustainable zero waste community strategy discussed is designed to serve the community for a healthier, safer and pollution less environment by applying cradle-to-cradle approach in all of the available waste production types and thus ensuring zero waste approach is being applied. In other words, ensuring that the produced output wastes are being used as input products within U.S.C. thus saving natural resources, reducing waste accumulation level, introducing new job opportunities and enhancing the economic standards of the community as well as its lifestyle and lastly reducing pollution; all leading to serving the community and having a balanced eco-system.

\section{Conclusion}

As much as urban communities are grouping citizens from different areas under different fields, being a safe place for families to live in where they can find all of their needs provided in terms of services, food, transportation and products as much as this is causing an environmental threat in terms of water, energy, resources, materials and wastes accumulation. As population increases in a certain area specially without any prior design for the community to occupy the high population, this leads to the urge in extracting more natural resources to be able to provide the needed services, leading to abusing the resources and causing its scarcity. Abusing natural resources means that it is a matter of time and these resources will not be available anymore for extraction and usage, leading to shortage of materials and lack of product sufficiency not only affecting the current population but also threatening the future ones. Thus there is a need to introduce the concept of sustainable community while integrating zero waste concept which is the main focus of this paper. The introduction of a proposed zero waste practical concept to conserve not only the waste but accordingly the water, air, materials, energy and natural resources in general. As illustrated earlier in Figure 6 that reaching a sustainable urban community while applying the zero waste concept is an easy step worth studying and implementing. Looking at the urban community products from wastes from C\&D, MSW, organic, yards and landscapes, grey and black water, all can be treated or undergo some processing steps resulting in a modified product mode like recycled products, organic fertilizers and treated water for irrigation and toilet flushing. By this, the urban sustainable community can be said to be a self-sustainable, closed-loop area that ensures the natural resources are put in appropriate first time usage and several reusage and thus preventing their depletion. 


\section{References}

[1] Business Sector Media, LLC. (2014, April 23). How Top Companies Are Creating Sustainable Brands. Retrieved from http://www.environmentalleader.com/2014/04/23/s potlight-on-the-hows-and-whys-of-sustainableproducts/

[2] City of Los Angeles Department of City Planning. (2015). Building Orientation. Retrieved from http://urbandesignla.com/resources/docs/LAWalka bilityChecklist/hi/LAWalkabilityChecklistCH05.pdf

[3] Community Health and Development. (2015). Understanding and Defining the community. (U. o. Kansas, Producer) Retrieved 2015, from http://ctb.ku.edu/en/table-ofcontents/assessment/assessing-community-needsand-resources/describe-the-community/main

[4] Eco Cycle-Building Zero Waste Communitites. (2012). Zero Waste: The choice for a sustainable community. Retrieved from http://www.ecocycle.org/zerowaste

[5] El-Haggar, S.M. (2007). Sustainable Industrial Design and Waste Management, Cradle-to-Cradle for sustainable development. Elsevier Academic Press.

[6] Entrepreneur. (2015, May 20). 10 things to consider when choosing a location for your business. Retrieved from http://www.entrepreneur.com/article/244866

[7] EPA. (2015). Penalty and Financial models. Retrieved from http://www2.epa.gov/enforcement/penalty-andfinancial-models

[8] European Regional Development Fund. (2015). Zero Waste Systems Analysis: Common Report. 5.

[9] Gaurav K. Singh, K. G. (2013). Solid Waste Management: Its Sources, Collection, Transportation and Recycling. 5, 1-2. Retrieved from http://www.ijesd.org/papers/507G0029.pdfGrassRoots Recycling Network. (2015). What is Zero Waste? Retrieved from http://www.grrn.org/page/what-zero-waste
[10] Institute for Zero Waste in Africa. (2015). Zero Waste. Retrieved from http://www.izwa.org.za/1Introduction $\% 20$ to $\% 20$ Zero $\% 20$ Waste.pdf

[11] Kenana Environmental and Fisheries. (2015). Retrieved from http://kenanaonline.com/users/lobnamohamed/post s/328080

[12] Mondal, P. (2015). 20 Important Characteristics of Urban Community. Retrieved from http://www.yourarticlelibrary.com/sociology/20important-characteristics-of-urban-communitysociology/4873/

[13] Natural Resources Defense Council. (2000). ELaw: What Started it All. Retrieved from http://www.nrdc.org/legislation/helaw.asp

[14] Rosen, Marc A. and Hossam A. Kishawy. (2012). Sustainable Manufacturing and Design: Concepts, Practices and Needs. Sustainability Journal, 4(2071-1050), 154-174. doi:10.3390/su4020154

[15] Smith, M. K. (2008). Theory, policy and practice, the encyclopaedia of informal education. Theory, policy and practice, the encyclopaedia of informal education. Retrieved from http://www.infed.org/community/sustainable_com munities and neighbourhoods.htm

[16] Tadesse, T. (2004). Solid Waste Management. Retrieved from http://www.cartercenter.org/documents/ethiopia_he alth/lecture/plain/environ_occ_health_students/ln_s olid_waste_final.pdf

[17] The Swedish Institue. (2013-2015). The Swedish Recycling Revolution. Retrieved from https://sweden.se/nature/the-swedish-recyclingrevolution/\#start

[18] U.S. Green Building Council. (2009). A Citizen's Guide to LEED for Neighborhood Development: How to tell if development is smart and green.

[19] University of Michigan. (2006). Urbanication and Global Change. Retrieved from http://www.globalchange.umich.edu/globalchange2 /current/lectures/urban_gc/ 